\title{
Wachstumsgeschwindigkeit der Peptidkette im Tabakmosaikvirus
}

\author{
H. Diringer, F. A. Anderer und G. Schramm \\ Max-Planck-Institut für Virusforschung, Tübingen \\ (Z. Naturforschg. 22 b, 1280-1291 [1967] ; eingegangen am 20. Juni 1967)
}

\begin{abstract}
The rate of incorporation of labelled amino acids into the complete tobacco mosaic virus (TMV), into soluble virus protein and into soluble cell proteins has been determined in discs of infected and healthy tobacco leaves. The rate of overall protein synthesis is increased by $50 \%$ in the infected leaves. At least $60 \%$ of the increase derives from the synthesis of virus-specific proteins and the synthesis of cellular proteins is not inhibited. The virus protein synthesis is strongly temperature dependent and shows a maximum at $28{ }^{\circ} \mathrm{C}$.

The exchange of free labelled amino acids between the external medium and the inner cellular pool reaches equilibrium within ten minutes. The influence of the exchange rate on the measurement of the kinetics of peptide chain synthesis is discussed in detail.

Discs from infected leaves were incubated for short periods at low temperatures in media containing ${ }^{3} \mathrm{H}$-tyrosine or ${ }^{3} \mathrm{H}$-proline. Peptides isolated after 5 minutes incubation at $15^{\circ} \mathrm{C}$ were found to be uniformly labelled with no apparent gradient of radioactivity from the $\mathrm{N}$ - to the C-terminus. The results indicate that the growth rate of the peptide chain at $15^{\circ} \mathrm{C}$ is probably higher than $2-3$ amino acids/sec and at $28{ }^{\circ} \mathrm{C}$ higher than 20 amino acids/sec. These values are higher than those for animal cells and similar to those for protein synthesis in Escherichia coli.

Comparison of the growth rate of TMV protein with rate of total protein synthesis and the number of ribosomes in the tobacco leaves indicate that only a small portion of the ribosomes takes part in cell protein synthesis.
\end{abstract}

Die Geschwindigkeit der Biosynthese von Peptidketten läßt sich auf zwei Wegen bestimmen. Man kann die Gesamtproteinsynthese einer Zellpopulation ermitteln und gleichzeitig aus dem RNS-Gehalt die Ribosomen-Zahl. Unter der Voraussetzung, daß jedes Ribosom an der Synthese einer Peptidkette beteiligt ist, läßt sich errechnen, wieviele Aminosäuren pro Sek. und Ribosom in die Peptidkette eingebaut werden. Auf diese Weise ergibt sich bei Escherichia coli eine Synthesegeschwindigkeit von etwa 40 Aminosäuren/sec. Eine andere Möglichkeit, die Synthesegeschwindigkeit $\mathrm{zu}$ messen, besteht in einem kurzzeitigen Angebot von radioaktiven Aminosäuren an Protein-synthetisierende Systeme. Es ist bekannt, daß die Ribosomen während der Proteinsynthese unvollständige Peptidketten verschiedener Länge enthalten ${ }^{1}$. Bei Zugabe einer markierten Aminosäure erscheinen im Sammelbecken der fertigen Peptidketten zunächst nur Peptide, die am Carboxylende markiert sind. Erst nach Ablauf der

1 J. A. Bishop, J. Leahy u. R. Schweet, Proc. nat. Acad. Sci. USA 46, 1030 [1960].

2 C. B. Anfinsen u. D. Steinberg, J. biol. Chemistry 189, 739 [1951].

3 R. E. Canfield u. C. B. Anfinsen, Biochemistry 2, 1073 [1963].

4 A. Goldstein u. B. J. Brown, Biochim. biophysica Acta [Amsterdam] 53, 438 [1961].

5 A. Yoshida u. T. Tolita, Biochim. biophysica Acta [Amsterdam] 37, 513 [1960].
Synthesezeit findet sich auch Radioaktivität am Aminoende. Es ergibt sich ein zunehmender Aktivitätsgradient vom N- zum C-Terminus, der die Wachstumsrichtung anzeigt. Dies wurde zum ersten Mal von Anfinsen und Steinberg ${ }^{2}$ bei der Synthese des Eieralbumins im Ovidukt von Hennen gefunden. Ähnliche Beobachtungen wurden seitdem von anderen Autoren an verschiedenen Objekten gemacht ${ }^{3-12}$.

Von Dintzis ${ }^{8,9}$ wurde die Hämoglobin-Snythese in Kaninchenreticulocyten untersucht. Um den Wert für die Synthesezeit zu erhalten, muß allerdings auch die Transportzeit berücksichtigt werden, die vergeht, bis die Aminosäure vom Außenmedium an den Synthese-Ort gelangt. Bei der Hämoglobinsynthese in Kaninchenreticulocyten ist diese Zeit bei $15^{\circ} \mathrm{C}$ unmeßbar klein, da die Radioaktivität sofort nach Versuchsbeginn am Carboxylende gefunden wurde. Bis zum Auftreten der Radioaktivität am Aminoende der $\alpha$-Kette vergingen etwa 6 Minuten. In dieser Zeit wurden 146 Aminosäuren verknüpft.

\footnotetext{
${ }^{6}$ D. N. Luck u. J. M. BarRy, J. molecular Biol. 9, 186 [1964].

7 R. E. Humbel, Proc. nat. Acad. Sci. USA 53, 853 [1965].

8 H. M. Dintzis, Proc. nat. Acad. Sci. USA 47, 247 [1961].

9 N. A. Naughton u. H. M. Dintzis, Proc. nat. Acad. Sci. USA 48, 1822 [1962].

10 V. M. Ingram u. R. M. Winslow, Cancer Res. 26, 1959 [1966].

11 B. Сolombo u. C. Baglioni, J. molecular Biol. 16, 51 [1966].

12 P. M. Kropf u. H. Lamfrom, Biochim. biophysica Acta [Amsterdam] 95, 398 [1965].
} 
Bei $37{ }^{\circ} \mathrm{C}$ verläuft die Synthese viermal schneller und dauert nur 1,5 Minuten. Die Synthesegeschwindigkeit beträgt also in diesem Falle 1,5 Aminosäuren/sec. Mit etwas veränderter Methodik wurde von Knopf und LAmfrom ${ }^{12}$ für die $\beta$-Kette des Hämoglobins eine Synthesezeit von $42 \pm 16$ Sek. bei $30^{\circ} \mathrm{C}$ ermittelt. Dies entspricht einer Synthesegeschwindig. keit von 2-3 Aminosäuren/sec. Bei $37^{\circ} \mathrm{C}$ könnte die Synthesegeschwindigkeit etwa doppelt so hoch sein.

Um einen Überblick über die Proteinsynthese im Tabakblatt und die Verteilung der angebotenen Aminosäuren auf die verschiedenen Proteinfraktionen zu erhalten, wurde zunächst geprüft, ob durch die Virusinfektion die gesamte Proteinsynthese gehemmt wird oder ob die Virussynthese eine zusätzliche Leistung der Zelle darstellt. Anschließend sollte die Synthesezeit für die aus 158 Aminosäuren bestehenden Peptidketten des Tabakmosaikvirus (TMV) gemessen werden. Hierzu war es jedoch nötig, zunächst einmal die Transportgeschwindigkeit der radioaktiven Aminosäuren vom Außenmedium in die Tabakzelle und die in umgekehrter Richtung verlaufende Rückdiffusion zu bestimmen. Außerdem mußte die Temperaturabhängigkeit der Proteinsynthese geprüft werden. Um die Verteilung der Radioaktivität in der Peptidkette zu bestimmen, wurde das Protein nach Markierung mit zwei verschiedenen Aminosäuren tryptisch gespalten und die spezifische Aktivität in den verschiedenen Positionen gemessen. Um auszuschließen, daß durch Aggregation der Proteinuntereinheiten zum kompletten Virus der Aktivitätsgradient verwischt wird, wurde der Aktivitätsgradient auch in dem löslichen, nicht aggregierten Virusprotein untersucht.

\section{Material und Methoden}

$$
\text { M a terialien }
$$

\begin{tabular}{|c|c|}
\hline $\begin{array}{l}\text { I-Tyrosin (spez. Aktivität } \\
2 \mathrm{C} / \mathrm{mM} \text { und } 38,8 \mathrm{C} / \mathrm{mM} \text { ) }\end{array}$ & \multirow{2}{*}{$\begin{array}{l}\text { Radiochemical } \\
\text { Center }\end{array}$} \\
\hline $\begin{array}{l}{ }^{14} \mathrm{C}-\text { Tyrosin (spez. Aktivität } \\
243 \mathrm{mC} / \mathrm{mM} \text { ) }\end{array}$ & \\
\hline $\begin{array}{l}{ }^{14} \mathrm{C} \text {-Prolin (spez. Aktivität } \\
158 \mathrm{mC} / \mathrm{mM} \text { ) }\end{array}$ & New England \\
\hline $\begin{array}{l}{ }^{3} \mathrm{H}-\text { Prolin (spez. Aktivität } \\
5 \mathrm{C} / \mathrm{mM} \text { ) }\end{array}$ & \\
\hline
\end{tabular}

${ }^{3} \mathrm{H}-\mathrm{N}$-Acetylserin (Markierung im Acetyl) wurde uns freundlicherweise von Dr. P. Duesberg überlassen.
Trypsin 3-mal kristallisiert

Chymotrypsin

L-Aminosäuren

sämtliche anderen

Chemikalien

Karl Roth, Karlsruhe

Serva, Heidelberg

Schuchardt, München

Merck, Darmstadt

Methoden

Radioaktivitätsmessungen: Sie wurden im Packard Tri-Carb vorgenommen. Proteine und TMV wurden in 1-m. methanolischer Hyaminlösung, wenn nötig unter Erwärmen bis auf $50{ }^{\circ} \mathrm{C}$, gelöst und dann in Toluollösung (5 g PPO, $300 \mathrm{mg}$ POPOP auf $1 l$ Toluol) gezählt. Wäßrige Proben wurden in Dioxanlösung ( $7 \mathrm{~g}$ PPO, $300 \mathrm{mg}$ POPOP, $100 \mathrm{~g}$ Naphthalin auf $1 l \mathrm{Di}$ oxan) gemessen.

Infektion der Pflanzen: Tabakpflanzen (Nicotiana tabacum var. Samsun) wurden im 3-Blatt-Stadium mit einer TMV-Lösung von $10^{-5} \mathrm{~g} / \mathrm{cm}^{3}$ in $0,02-m$. Phosphatpuffer vom $p_{\mathrm{H}}$-Wert 6,0 unter Verwendung von Corund infiziert. Dann wurden die Pflanzen unter Leitungswasser abgespült. Die Einbauversuche wurden jeweils am 5 . bis 6 . Tag nach der Infektion vorgenommen.

Für die Einbauversuche wurden aus den Tabakblättern Scheibchen mit einem Durchmesser von $1,3 \mathrm{~cm}$ und einem Gewicht von $19-23 \mathrm{mg}$ ausgestochen und jeweils 30 Scheibchen in Petrischalen von $8 \mathrm{~cm}$ Durchmesser auf gehärtetem Filterpapier, das mit halb-konzentrierter Vickerey-Lösung durchfeuchtet war, ausgelegt. Die Blätter wurden vor dem Auslegen mit demselben Lösungsmittel gewaschen.

Proteinsynthese in gesunden und infizierten Blättern: 80 Blattscheiben wurden, wie oben beschrieben, bei $15{ }^{\circ} \mathrm{C}$ mit ${ }^{3} \mathrm{H}$-Prolin $(5 \mathrm{C} / \mathrm{mM})$ bzw. bei $25^{\circ} \mathrm{C}$ mit ${ }^{3} \mathrm{H}$-Tyrosin $(2 \mathrm{C} / \mathrm{mM})$ bebrütet. Danach wurden die Blättchen kurz mit Wasser abgespült und in $5 \mathrm{~cm}^{3}$ 0,1-m. Phosphatpuffer $p_{\mathrm{H}} 7$ homogenisiert. Die $5 \mathrm{~cm}^{3}$ Puffer enthielten $10 \mathrm{mg}$ Träger-TMV und etwa $250 \mu \mathrm{g}$ nichtaktive Aminosäure. Nach 15 Min. Zentrifugation bei $13000 \mathrm{Upm}$ im 40 Spinco-Rotor wurde aus dem verbleibenden Überstand das Virus 100 Min. bei 40000 Upm abgeschleudert, durch differentielle Zentrifugation und isoelektrische Fällung gereinigt und die spezifische Aktivität bestimmt. Daraus wurde die in $10 \mathrm{mg}$ TMV enthaltene Aktivität berechnet.

Der Überstand wurde nach der TMV-Entfernung $20 \mathrm{Stdn}$. gegen 3-mal $10 l$ Wasser dialysiert, die Proben mit $0,5 \mathrm{~cm}^{3}$ Phosphat-Puffer $p_{\mathrm{H}} 7,0$ versetzt, um die Trübung zu beseitigen. Anschließend wurden $500 \mu \mathrm{g}$ TMV und $0,1 \mathrm{~cm}^{3}$ eines TMV-Antiserums hinzugegeben. Mit $1-m$. $\mathrm{KH}_{2} \mathrm{PO}_{4}$-Puffer wurde auf $p_{\mathrm{H}} 5,8$ eingestellt, zur Ausflockung eine Stde. bei $37^{\circ} \mathrm{C}$ belassen, dann über Nacht bei $4{ }^{\circ} \mathrm{C}$. Das ausgefallene Protein wurde sedimentiert, zweimal mit 0,1-m. Puffer vom $p_{\mathrm{H}} 5,8$ gewaschen, dann mit Äthanol, schließlich mit Äther. Den Rückstand zählte man in Hyamin/Toluol. 


\begin{tabular}{|c|c|c|c|c|c|c|}
\hline \multirow[b]{2}{*}{ Fraktion } & \multicolumn{2}{|c|}{$\begin{array}{c}\mathrm{I} \\
\text { Prolin }[5 \mathrm{C} / \mathrm{mM}] \\
30 \mathrm{Min} .15^{\circ} \mathrm{C} \\
\text { Zerfälle } / \mathrm{min} \text { in } 10^{4}\end{array}$} & \multicolumn{2}{|c|}{$\begin{array}{c}\text { II } \\
\text { Tyrosin }[2 \mathrm{C} / \mathrm{mM}] \\
40 \mathrm{Min} .25^{\circ} \mathrm{C} \\
\mathrm{ZPM} \text { in } 10^{4}\end{array}$} & \multicolumn{2}{|c|}{$\begin{array}{c}\text { III } \\
\text { Tyrosin }[2 \mathrm{C} / \mathrm{mM}] \\
6 \mathrm{Stdn} .25^{\circ} \mathrm{C} \\
\mathrm{ZPM} \mathrm{in} 10^{4}\end{array}$} \\
\hline & infiziert & gesund & infiziert & gesund & infiziert & gesund \\
\hline Virus & 11,4 & 0,1 & 4,5 & 0,53 & 40,0 & 2,0 \\
\hline lösl. Virusprot. * & 85,2 & 13,3 & 4,68 & 1,72 & 25,0 & 7,0 \\
\hline cytoplasm. Prot. & 220,0 & 191,0 & 20,0 & 18,0 & 290,0 & 218,0 \\
\hline Summe & 316,6 & 204,4 & 29,18 & 20,25 & 355,0 & 227,0 \\
\hline Verhältnis inf./ges. & \multicolumn{2}{|c|}{1,55} & \multicolumn{2}{|c|}{1,45} & \multicolumn{2}{|c|}{1,56} \\
\hline
\end{tabular}

Tab. 1. Einbau von radioaktiv markiertem Prolin und Tyrosin in die Proteinfraktion gesunder und infizierter Tabakpflanzen. * Mit Anti-TMV-Serum bei $p_{\mathrm{H}} 5,8$ gefällt.

Einen aliquoten Teil des Überstandes der Antiserum-Fällung zählte man bei den Versuchen I und III direkt und berechnete die Radioaktivität des verbleibenden Proteins.

Bei Versuch II wurde mit Trichloressigsäure (Endkonzentration 5\%) gefällt, das Sediment mehrmals mit 5-proz. Trichloressigsäure, dann mit 70-proz. Äthanol, Äthanol und Äther gewaschen und anschließend gezählt (Ergebnisse s. Tab. 1).

Temperaturabhängigkeit der TMV-Synthese: 30 infizierte Blattscheiben wurden nach dem Waschen in halb-konzentrierter Vickerey-Lösung auf einem harten Filter ausgelegt und mit einem Filterpapier trocken getupft. Nach einer halben Stde. Vorinkubation im beleuchteten Thermostaten wurden die Proben $30 \mathrm{Min}$. bei $3,5,10,15,20,25$ und $30^{\circ} \mathrm{C}$ mit $50 \mu \mathrm{C}$ ${ }^{3} \mathrm{H}$-Tyrosin $(2 \mathrm{C} / \mathrm{mM})$ in $2 \mathrm{~cm}^{3}$ halb-konzentrierter V i ckerey-Lösung in jeder Schale inkubiert. Danach stoppte man den Einbau der Aminosäure durch Einfrieren in Aceton-Trockeneis. Unter Zugabe von $10 \mathrm{mg}$ TMV wurden die Proben homogenisiert und das Virus viermal durch differentielle Zentrifugation gereinigt und die spezifische Aktivität bestimmt.

Aufnahme von Tyrosin und N-Acetylserin: Infizierte Blattscheiben wurden bei $23{ }^{\circ} \mathrm{C}$, wie oben beschrieben, auf Papierfilter ausgelegt. Nach einer Stde. gab man $50 \mu \mathrm{C}{ }^{3} \mathrm{H}$-markiertes Substrat $(200 \mathrm{mC} / \mathrm{mM})$ in $4 \mathrm{~cm}^{3}$ halb-konzentierter Vickerey-Lösung zu und nahm in bestimmten Zeitabständen ein Blättchen heraus. Dieses wurde schnell unter fließendem Wasser abgespült, durch $5 l$ Wasser mit inaktivem Substrat gezogen, anschließend nochmals durch $1 l$ Wasser. Dann wurde es auf einem Filterpapier trocken getupft und in $2 \mathrm{~cm}^{3}$ Wasser bzw. Äthanol 15 Minuten ausgekocht. Die wäßrigen bzw. alkoholischen Tyrosin-Extrakte untersuchten wir papierchromatographisch im System Butanol - Wasser-Eisessig 4:5:1 und maßen die Verteilung der Radioaktivität im Packard Scanner. Die Radioaktivität hatte den gleichen $R_{f}$-Wert wie Tyrosin.

Abgabe des Tyrosins an das Außenmedium: 16 Tabakscheiben wurden $45 \mathrm{Min}$. in $4 \mathrm{~cm}^{3}$ halb-konzentrierter Vickerey-Lösung mit $50 \mu \mathrm{C}{ }^{3} \mathrm{H}$-Tyrosin $(200 \mathrm{mC} / \mathrm{mM})$ inkubiert. Dann wurden jeweils 2 Blättchen in Abständen von einer Min. herausgenommen, schnell und gut unter Leitungswasser, dann in $5 l$ gesättigter Tyrosin-Lösung abgespült und auf einem Filter abgetupft. Anschließend wurden je 2 Scheiben in ein Zählglas mit $1 \mathrm{~cm}^{3}$ der V i c k e r e y - Lösung gegeben, die $0,25 \mu \mathrm{M}$ inaktives Tyrosin in $4 \mathrm{~cm}^{3}$ enthielt. In gewissen Zeitabständen wurden die Blättchen aus dem Glas genommen, die Lösung zur Entfernung von ${ }^{3} \mathrm{H}$-Wasser über $\mathrm{P}_{2} \mathrm{O}_{5}$ getrocknet, dann in $5 \mathrm{~cm}^{3}$ Dioxanlösung und in $0,5 \mathrm{~cm}^{3}$ Wasesr gezählt.

\section{Verteilung der spezifischen Radioaktivität im TMV-Pro- tein nach Inkubation mit ${ }^{3} \mathrm{H}$-Tyrosin und ${ }^{3} \mathrm{H}$-Prolin}

Die spezifische Aktivität wurde durch das Verhältnis der ${ }^{3}$-H-markierten Aminosäure zum ${ }^{14} \mathrm{C}$-markierten Trägervirus ermittelt. Zur Darstellung des markierten Trägervirus wurden 85 infizierte Blattscheiben $6 \mathrm{Stdn}$. mit $25 \mathrm{mC}{ }^{14} \mathrm{C}$-Tyrosin bzw. ${ }^{14} \mathrm{C}$-Prolin in $4 \mathrm{~cm}^{3}$ halb-konzentrierter V i c k e r e y - Lösung bei $25^{\circ} \mathrm{C}$ gehalten. Die Blättchen wurden dann eingefroren und zerkleinert unter Zusatz von $5 \mathrm{~cm}^{3}$ Phosphatpuffer. Zur Entfernung der groben Zellbruchstücke wurde 15 Min. bei $13000 \mathrm{Upm}$ (Spinco-Zentrifuge 40-er Rotor) zentrifugiert. Aus dem Überstand wurde das Virus bei $40000 \mathrm{Upm}$ in $100 \mathrm{Min}$. sedimentiert. Zur weiteren Reinigung des Virus wurde die Zentrifugation in 0,1-m. Phosphatpuffer zweimal wiederholt. Zur Bestimmung der spezifischen Aktivität wurde die Virusmenge spektrophotometrisch ermittelt. Ein aliquoter Teil der TMV. Lösung wurde über $\mathrm{P}_{2} \mathrm{O}_{5}$ getrocknet und die Radioaktivität in Hyamin-Toluol-Lösung gemessen.

Im Hauptversuch wurden die infizierten Blattscheiben, wie oben beschrieben, nach einer Vorinkubation im Thermostaten mit $4 \mathrm{~cm}^{3}$ halb-konzentrierter V i ck e r e y-Lösung versetzt. Diese enthielt $400 \mu \mathrm{C}$ ${ }^{3} \mathrm{H}$-Tyrosin bzw. ${ }^{3} \mathrm{H}$-Prolin. Der Einbau wurde nach bestimmten Zeiten durch Einfrieren in Aceton-Trockeneis gestoppt. Bis zur Verarbeitung wurden die Schalen in einer Kühltruhe bei $-12{ }^{\circ} \mathrm{C}$ aufbewahrt. Nach dem Auftauen und kurzem Waschen in 0,1-m. Phosphatpuffer wurden die Blättchen, wie oben, in $5 \mathrm{~cm}^{3}$ Phosphatpuffer homogenisiert, wobei $10 \mathrm{mg}$ inaktives TMV als Träger und $100 \gamma / \mathrm{cm}^{3}$ inaktive Aminosäure zugesetzt wurden. Dann wurde das Virus, wie oben, nach Entfernung der groben Zellbruchstücke bei $13000 \mathrm{Upm}$, bei $40000 \mathrm{Upm}$ sedimentiert. Danach wurde noch zweimal durch differentielle Zentrifugation gereinigt. Darauf wurde das Virus bei $p_{H} 3,9$ isoelektrisch gefällt und niedertourig abgeschleudert. Diese Fällung wurde noch zweimal wiederholt und schließlich noch zweimal 


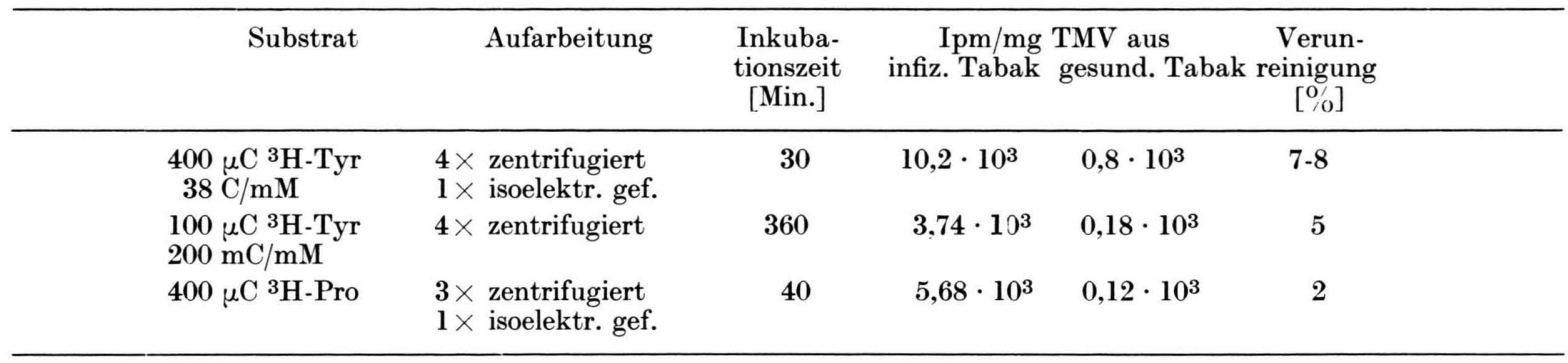

Tab. 2. Bestimmung der Beimischung von Normal- zu Virusprotein bei verschiedener Aufarbeitung.

in 0,2-m. Phosphatpuffer $p_{\mathrm{H}} 7$ differentiell zentrifugiert. Die Ausbeute betrug bei dieser Reinigung 40 bis $50 \%$ der zugegebenen TMV-Menge. Vor der weiteren Aufarbeitung wurde ${ }^{14} \mathrm{C}$-markiertes Virus zugefügt in einer Menge, die eine gleichzeitige ${ }^{3} \mathrm{H}$-Bestimmung zuließ.

Kontrollversuche mit ${ }^{14} \mathrm{C}$-markiertem Virus ergaben, daß sich durch weitere Reinigungsschritte die spezifische Aktivität des isolierten Virus nicht mehr änderte.

Um eine eventuelle Verunreinigung durch Wirtsprotein auszuschließen, wurden nebeneinander infizierte und nicht-infizierte Tabakblätter mit ${ }^{3} \mathrm{H}$-Aminosäuren bebrütet und anschließend Trägervirus zugesetzt. Das zugesetzte Trägervirus enthielt nach der Reinigung bei den nicht-infizierten Blättern höchstens $7-8 \%$ der ${ }^{3} \mathrm{H}$ Aktivität des Virusmaterials aus infizierten Blättern (s. Tab. 2).

Zur Entfernung der Nucleinsäure wurde das isolierte Virus (etwa $4-5 \mathrm{mg}$ ), gelöst in $3 \mathrm{~cm}^{3} 0,02-\mathrm{m}$. Phosphatpuffer, $p_{\mathrm{H}} 7,0$, mit $1 \mathrm{~cm}^{3} 80$-proz. Phenol bei Zimmertemperatur kräftig geschüttelt. Anschließend wurden die Phasen durch Zentrifugation getrennt, die wäßrige abgezogen und verworfen.

Im Phenol, versetzt mit wenig kristallinem Ammoniumacetat, wurde durch tropfenweise Zugabe von $10 \mathrm{~cm}^{3}$ Äthanol und $5 \mathrm{~cm}^{3}$ Äther unter Umschütteln das Protein ausgefällt. Nach 3 Stdn. bei $4{ }^{\circ} \mathrm{C}$ wurde es abzentrifugiert, zweimal mit $5 \mathrm{~cm}^{3}$ Äthanol/ Äther (2:1) und einmal mit Äther gewaschen. Anschließend wurde $2 \mathrm{Stdn}$. bei $45{ }^{\circ} \mathrm{C}$ getrocknet.

Wie aus dem Formelbild der Peptidkette des TMV (Abb. 1) zu erkennen ist, sind bei der tryptischen Spaltung 4 Tyrosin-haltige Peptide zu erwarten. Peptid $\mathrm{P}_{1}$ (Positionen 1-41) enthält Tyrosin in Position 2, das Peptid 69-71 in Position 70, das Peptid 72-90 in Position 72 und das Peptid 135-141 enthält Tyrosin in Position 137. $P_{1}$ ist sehr schwer löslich und kann leicht durch isoelektrische Fällung von den anderen Peptiden getrennt werden.

Zur tryptischen Spaltung wurde das getrocknete TMV-Protein mit $0,1-0,2 \mathrm{~cm}^{3} 0,1-n$. $\mathrm{NaOH}$ bei $45^{\circ}$ etwa 1 Stde. gut durchfeuchtet, bis fast alles gelöst war und dann langsam mit dest. Wasser auf ein Volumen von $8 \mathrm{~cm}^{3}$ gebracht. Jetzt wurde mit $0,1-n$. $\mathrm{NaOH}$ ein $p_{\mathrm{H}}$ von 9,0 eingestellt und $30 \mu \mathrm{l}$ Trypsinlösung ( 1 bis $1,5 \mathrm{mg}$ Enzym je $\mathrm{cm}^{3}, \mathrm{n} / 16-\mathrm{HCl}, 12 \mathrm{Stdn}$. bei $37{ }^{\circ} \mathrm{C}$ vorinkubiert zur Inaktivierung des Chymotrypsins) zugegeben. Nach einer Stde. bei $37{ }^{\circ} \mathrm{C}$ wurde nochmals die gleiche Menge Ferment hinzugefügt, der $p_{\mathrm{H}}$-Wert nachgestellt und die Probe über Nacht im Brutschrank belassen. Am Morgen wurde mit 0,1-n. $\mathrm{HCl}$ ein $p_{\mathrm{H}}$ von 4,2 eingestellt. Dabei fiel das Peptid $\mathrm{P}_{1}$ mit den Posi-
65

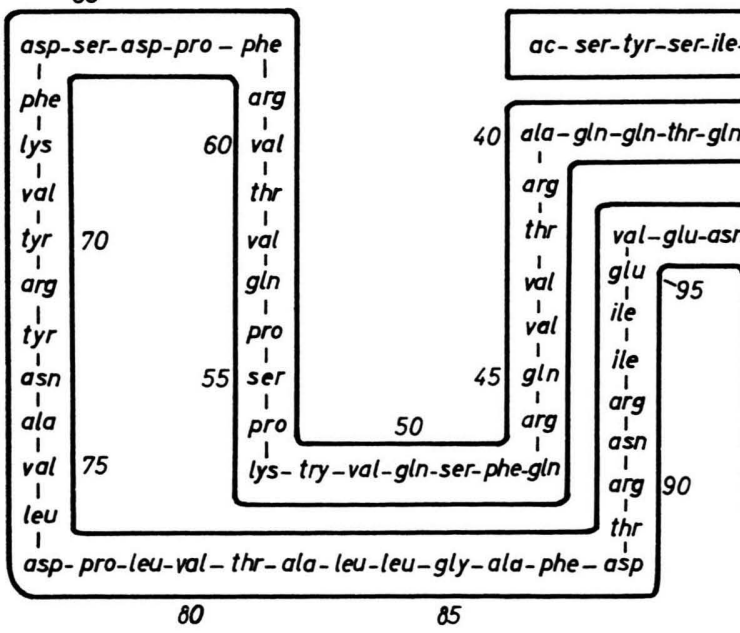

5 10 15

Abb. 1. Reihenfolge der Aminosäuren im Tabakmosaikvirus. 
tionen $1-41$ aus. Es wurde abzentrifugiert, mit $1-2$ Tropfen verdünnter $\mathrm{NaOH}$ aufgelöst und aus einem Volumen von $1,5-2 \mathrm{~cm}^{3}$ nochmals, wie oben, gefällt. Nach Trocknen über $\mathrm{P}_{2} \mathrm{O}_{5}$ wurde es in Hyamin gelöst und gezählt. Um Reste des radioaktiven $\mathrm{P}_{1}$ aus dem Úberstand $\mathrm{zu}$ entfernen, wurde nochmals nicht-aktives $\mathrm{P}_{1}$-Peptid zugesetzt und die Fällung wiederholt.

Die Aufarbeitung der weiteren Tyrosin-haltigen Peptide wurde zuerst nach der Fingerprint-Methode von Woody und KNIGHT ${ }^{13}$ versucht, doch zeigte sich, daß hierbei die Tritium-Aktivität der Peptide teilweise verloren ging. Die Trennung gelang ohne Tritium-Verlust mit Sephadex G-25, da hierbei ein saures Medium vermieden werden. Das tryptisch gespaltene, von radioaktivem $\mathrm{P}_{1}$ befreite Virusprotein wurde in $0,4 \mathrm{~cm}^{3} n / 10$ $\mathrm{NaOH}$ klar gelöst und auf eine. Säule aus Sephadex G-25 $(75 \cdot 2 \mathrm{~cm})$ aufgetragen. Es wurde dann mit $2 \mathrm{~cm}^{3}$ des Elutionspuffers $\left(2 \mathrm{~g}\left(\mathrm{NH}_{4}\right)_{2} \mathrm{CO}_{3}\right.$ in $4 . l$ Wasser) nachgespült und dann mit einer Durchlaufgeschwindigkeit von $50 \mathrm{~cm}^{3} /$ Stde. eluiert. $5 \mathrm{~cm}^{3}$ Fraktionen wurden aufgefangen und die einzelnen Fraktionen, wie in Abb. 2 angegeben, getrennt und die Radioaktivität be-

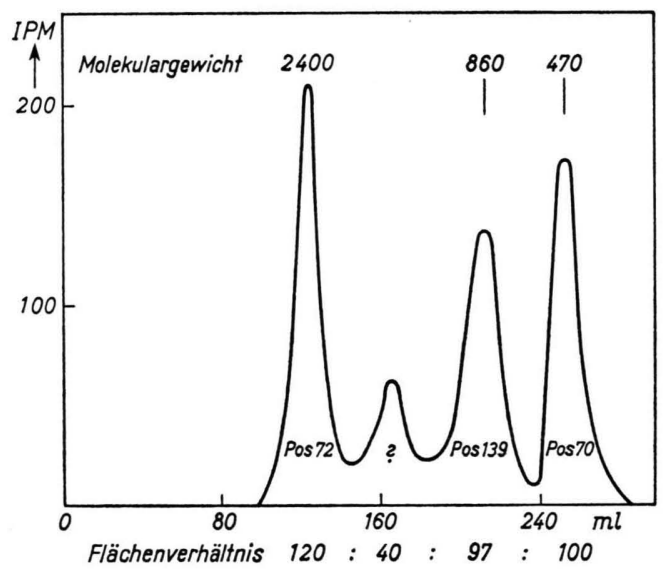

Abb. 2. Trennung der ${ }^{3} \mathrm{H}-\mathrm{T}$ yrosin-Peptide auf Sephadex G-25.

stimmt. Zwischen dem Peptid mit Position 72 und dem mit Position 139 fand sich meist ein weiteres radioaktives Peptid, dessen Aktivität etwa $10 \%$ der insgesamt auf die Säule gebrachten Radioaktivität betrug. Wahrscheinlich entsteht dieses Peptid durch unvollständige tryptische Spaltung des Virus-Proteins.

Kontrollversuche: Die tryptischen Tyrosin-Peptide erwiesen sich als elektrophoretisch einheitlich. Ein Austausch des Tritiums mit dem Elutionsmittel erfolgte nicht. Das ${ }^{3} \mathrm{H} /{ }^{14} \mathrm{C}$-Verhältnis in $\mathrm{P}_{1}$ blieb auch nach wiederholter Chromatographie konstant (Tab.3). Ebenso wurde nach längeren Einbauzeiten in allen anderen Tyrosin-Positionen stets die gleiche spezifische Aktivität gefunden (Tab. 4).

In einem weiteren Versuch wurde geprüft, ob das durch isoelektrische Fällung gewonnene Peptid $P_{1}$

13 B. R. Woody u. C. A. Knight, Virology 9, 359 [1959].

\begin{tabular}{cr}
\hline & ${ }^{3} \mathrm{H} /{ }^{14} \mathrm{C}$ \\
\hline Ausgang & 3,23 \\
1-mal chromatographiert & 3,60 \\
2-mal chromatographiert & 3,35 \\
Mittelwert & $3,40 \pm 0,20$ \\
\hline
\end{tabular}

Tab. $3 .{ }^{3} \mathrm{H} /{ }^{14} \mathrm{C}$-Verhältnis nach wiederholter Chromatographie.

\begin{tabular}{crrl}
\hline Versuch & Tyr-Position & ${ }^{3} \mathrm{H} /{ }^{14} \mathrm{C}$ & $\begin{array}{l}14 \mathrm{C}-\mathrm{Ipm} \\
\mathrm{mM} \text { Tyr }\end{array}$ \\
\hline \multirow{2}{*}{$\mathrm{I}$} & 2 & 8,9 & \\
& 70 & 10,1 & \\
& 72 & 9,7 & \\
II & 139 & 8,7 & \\
& 2 & & $8,9 \cdot 10^{4}$ \\
& 70 & & $9,6 \cdot 10^{4}$ \\
III & 139 & & $6,4 \cdot 10^{4}$ \\
& 2 & & $8,1 \cdot 10^{3}$ \\
& 70 & & $8,0 \cdot 10^{3}$ \\
& 139 & & $7,9 \cdot 10^{3}$ \\
\hline
\end{tabular}

Tab. 4. Beweis für die gleichförmige Markierung in den TyrPositionen nach längerer Inkubation. Bei Versuch I wurde ${ }^{3} \mathrm{H}$-markiertes TMV mit ${ }^{14} \mathrm{C}$-markiertem TMV vermischt, bei den Versuchen II und III wurde die Aktivität des ${ }^{14} \mathrm{C}$-markierten TMV mit der chemisch bestimmten Aminosäure-Konzentration verglichen.

durch die drei anderen Tyrosin-Peptide verunreinigt ist. Hierzu wurde ${ }^{14} \mathrm{C}$-Tyrosin-TMV und ${ }^{3} \mathrm{H}$-Tyrosin-TMV durch langzeitige Inkubation hergestellt. Aus dem ersteren wurde durch tryptische Spaltung das Peptid ${ }^{14} \mathrm{C}$-Tyrosin $\mathrm{P}_{1}$ gewonnen, aus dem letzteren die übrigen tryptischen Peptide. Dann wurden die Peptide miteinander vermischt und wieder ausgefällt. Im Überstand und auch im $\mathrm{P}_{1}$ wurden die ${ }^{3} \mathrm{H}$ - und ${ }^{14} \mathrm{C}$-Aktivitäten bestimmt. Die Verunreinigung von $\mathrm{P}_{1}$ durch andere tryptische Peptide betrug höchstens 3 Prozent. Gleichzeitig zeigte der Versuch, daß $15 \%$ des $\mathrm{P}_{1}$ bei der Fällung in Lösung bleibt. Dieser Rest wurde durch Nachfällen mit inaktivem $\mathrm{P}_{1}$ entfernt.

Isolierung der Prolin-Peptide: Bei den Untersuchungen über den Prolin-Einbau war die Versuchstechnik dieselbe wie bei den Versuchen mit ${ }^{14} \mathrm{C}$-Tyrosin. Die Auftrennung der tryptischen Prolin-Peptide über die Sephadex-Säule gelang jedoch nicht zufriedenstellend. Eine eindimensionale Elektrophorese bei $p_{\mathrm{H}} 7$ erwies sich als vorteilhafter, nachdem $\mathrm{P}_{1}$ wie üblich abgetrennt wurde. Die Elektrophorese wurde in CollidinEisessig auf Whatman 3 Papier $(12.57 \mathrm{~cm})$ durchgeführt. Die Probe wurde in der Mitte des Streifens auf das feuchte Papier aufgetragen und 3,5 Stdn. bei $3200 \mathrm{~V}$ und $40 \mathrm{~mA}$ getrennt. Hierbei wurden 3 Peptide außerhalb der Startregion erhalten und zwar diejenigen mit den Prolin-Positionen 54/56, 63 und 102, während das vorher ausgefällte $\mathrm{P}_{1}$ die Positionen 7 und 21 gemeinsam enthielt. 
Berechnung der Synthese-Geschwindigkeit der Peptidketten aus dem Ribosomen-Gehalt

Für die Proteinsynthese von $E$. coli wurden folgende Daten zugrundegelegt.

Dauer eines Generationscyclus bei $37{ }^{\circ} \mathrm{C}$

Proteingehalt je Zelle

RNS-Gehalt je Zelle

20 Min.

$1,25 \cdot 10^{-13} \mathrm{~g}$

$3 \cdot 10^{-14} \mathrm{~g}$

Ribosomen-RNS $=85 \%$ der Gesamt-RNS, ihr Molgewicht beträgt $1,5 \cdot 10^{6}$. Ein Bakterium enthält also $2 \cdot 10^{-20}$ Mol Ribosomen bzw. $1 \cdot 10^{-15}$ Mol Aminosäuren. Da diese Proteinmenge in 20 Min. hergestellt wird, werden also bei $37^{\circ} \mathrm{C} 44$ Aminosäuren/Ribosom/ Sek. eingebaut. Für die Synthesegeschwindigkeit des Proteins im Tabakblatt wurden folgende Daten zugrunde gelegt.
Blattgewicht
RNS-Gehalt
$640 \mathrm{mg}$
$640 \mu \mathrm{g}$.

Hieraus ergibt sich ein Ribosomen-Gehalt von $4,3 \cdot 10^{-4} \mu \mathrm{Mol}$ in $640 \mathrm{mg}$ Blattmaterial.

In $60 \mathrm{Min}$. wurden $0,73 \mu \mathrm{C}$ oder $0,37 \cdot 10^{-2} \mu \mathrm{Mol}$ Tyrosin eingebaut. Der Tyrosin-Gehalt des TMV-Proteins beträgt 2,5-Mol-Prozent. In $640 \mathrm{mg}$ Blattmaterial wurden also in $60 \mathrm{Min}$. $0,15 \mu \mathrm{Mol}$ Aminosäuren eingebaut. Wenn alle Ribosomen ständig mit der Proteinsynthese beschäftigt wären, so würde ein Ribosom in einer Sek. 0,1 Aminosäure einbauen.

\section{Ergebnisse}

\section{Die Berechnung der Synthesezeit}

Wenn in der Transportzeit $t_{1}$ der Ausgleich der Radioaktivität zwischen radioaktiven Aminosäuren im Außenmedium und nicht markierten freien Aminosäuren im Zellinnern abgeschlossen ist, und somit die spezifische Radioaktivität der Aminosäuren im Zellinnern konstant bleibt, sollte die spezifische Radioaktivität $R$ in den verschiedenen Positionen proportional mit der Zeit ansteigen, wobei der Anstieg in der niederen Position $n_{1}$ am Amino-Ende gegenüber der höheren Position $n_{2}$ am CarboxylEnde um die Synthesezeit $t_{\mathrm{s}}$ verzögert ist. $R_{2}-R_{1}=$ $\alpha \cdot t_{\mathrm{s}}$ (Abb. 3).

Aus der Differenz $\Delta R$ in den zwei verschiedenen Positionen und der Neigung $\alpha$ läßt sich also $t_{\mathrm{S}}$ berechnen. Dieses Verfahren wurde von KNopF und LAMFrom $^{12}$ zur Bestimmung der Synthesezeit für die $\beta$-Kette des Hämoglobins angewandt. Sie fanden, daß 2 Min. nach Versuchsbeginn $R_{1}$ und $R_{2}$ linear und parallel zueinander ansteigen. Wenn $t_{\mathrm{s}}$ sehr klein ist gegenüber der Inkubationszeit $T$, so wird die Bestimmung von $\Delta R$ ungenau, da es sich als Differenz zweier großer Zahlen ergibt. $T$ muß

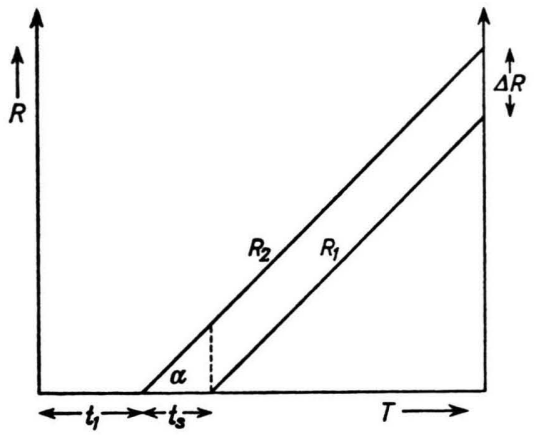

Abb. 3. Berechnung der Synthesezeit. $t_{1}=$ Transportzeit, $t_{\mathrm{S}}=$ Synthesezeit, $T=$ Inkubationszeit, $R_{1}$ und $R_{2}=$ spezifische Radioaktivität in den Positionen $n_{1}$ und $n_{2}$.

also möglichst klein gewählt werden, doch sind der Verkürzung experimentelle Grenzen gesetzt, da bei zu geringem Einbau die $\Delta R$-Werte ebenfalls unmeßbar klein werden. Eine andere Möglichkeit besteht darin, durch Herabsetzung der Temperatur $t_{\mathrm{s}}$ zu verlängern. Wenn in der kleinsten experimentell möglichen Versuchszeit kein Unterschied in den spezifischen Radioaktivitäten der einzelnen Positionen auftritt, so läßt sich nur der Schluß ziehen, daß $t_{\mathrm{s}} \ll T$, es kann also nur ein oberer Grenzwert angegeben werden. Wenn der Austausch der Radioaktivität zwischen Innen- und Außenmedium in der Zeit $t_{1}$ noch nicht abgeschlossen ist, so kann der Anstieg von $R$ in den verschiedenen Positionen anfangs nicht linear sein, doch sollte die Differenz $\Delta R$ im anschließenden linearen Bereich erhalten bleiben. Ein solcher Fall wurde offenbar von KNopF und Lamfrom ${ }^{12}$ beobachtet. Wenn $t_{\mathrm{s}}$ so klein sein sollte, daß $\Delta R$ nicht meßbar ist, so kann also auch in diesem Fall auf einen oberen Grenzwert der Synthesezeit geschlossen werden.

Falls die Synthesegeschwindigkeit in der Peptidkette gegen das C-Ende abnehmen sollte, wie das von anderen Autoren ${ }^{10}$ angenommen wurde, so müßte die Neigung $\alpha$ für $R_{1}$ und $R_{2}$ verschieden sein. Dies ist offenbar beim Hämoglobin nicht der Fall.

\section{Die Proteinsynthese im gesunden und infizierten Tabak}

Aus der Verteilung des radioaktiv markierten Tyrosins auf die Wirtsproteine und die Virus-spezifischen Proteine läßt sich feststellen, ob die Synthese des Virusproteins auf Kosten der Synthese der Zellproteine verläuft oder eine zusätzliche Leistung der Zelle darstellt. Um diese Frage zu entscheiden, wur- 
den gesunde und infizierte Tabakblätter mit radioaktivem Tyrosin bebrütet. Die Infektion der Tabakblätter mit TMV erfolgte 5-6 Tage vor Versuchsbeginn, so daß bei der Inkubation mit Tyrosin eine maximale Geschwindigkeit der Virussynthese zu erwarten war. Aus den inkubierten Blattscheiben wurden die löslichen Proteine mit Phosphatpuffer von $p_{\mathrm{H}} 7$ extrahiert. Nach Zugabe von Trägervirus wurden die vollständigen Virusteilchen abgeschleudert und aus dem Überstand das Virusprotein mit Antiserum gefällt. Die in Lösung verbliebenen Zellproteine wurden entweder durch Fällung mit Trichloressigsäure oder durch Dialyse gereinigt und die Radioaktivität bestimmt. Das Ergebnis dieser Versuche ist in Tab. 1 zusammengefaßt. Die gesamte Proteinsynthese war in den infizierten Tabakblättern um $50 \%$ erhöht. Etwa $60 \%$ des zusätzlichen Proteins entfielen auf Virus-spezifische Proteine (komplettes Virus + lösliches Virusprotein). Die Differenzierung zwischen kompletten Virusteilchen und löslichem Virusprotein ist schwierig, da die Trennung dieser beiden nicht zuverlässig gelingt. Bei diesen langen Versuchszeiten, die zwischen 0,5 und $6 \mathrm{Stdn}$. lagen, spielte die Transportgeschwindigkeit des Tyrosins keine Rolle. Bei kurzzeitigen Einbauversuchen muß jedoch hierauf geachtet werden.

\section{Transportgeschwindigkeit des Tyrosins}

Um die späteren Versuche auswerten zu können, mußte der Konzentrationsausgleich zwischen der radioaktiven Aminosäure im Außenmedium und den freien Aminosäuren im Zellinnern gemessen werden. Hierzu wurden Scheiben aus infizierten Tabakblättern mit radioaktivem Tyrosin inkubiert, sorgfältig gewaschen und das in der Zelle enthaltene Tyrosin mit siedendem Wasser oder 80-proz. warmen Äthanol extrahiert. Bei der papierchromatographischen Kontrolle fand sich die Radioaktivität im Fleck des freien Tyrosins, die Menge an anderen radioaktiven Komponenten konnte vernachlässigt werden. Zum Vergleich wurden auch Versuche mit einer Acetylaminosäure, nämlich $N$-Acetylserin, durchgeführt. Die Ergebnisse sind in Abb. 4 wiedergegeben.

In den ersten zehn Min. stieg die Radioaktivität des Tyrosins im Zellinnern schnell an. Danach nahm sie weiterhin linear mit der Zeit zu, wenn auch etwas langsamer. Beim $N$-Acetylserin war der Anstieg der Radioaktivität nach 10-15 Min. beendet und diese blieb dann konstant. Die unterschiedliche Aufnahme der beiden Stoffe könnte darauf beruhen, daß
Tyrosin ein wichtiges Substrat im Stoffwechsel der Pflanze ist und daher ein aktiver Transportmechanismus besteht, der unter Energieverbrauch gegen ein

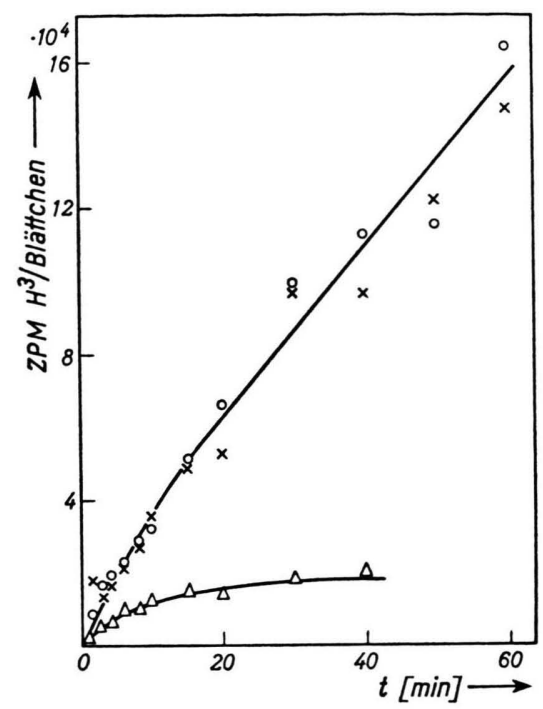

Abb. 4. Anstieg des freien ${ }^{3} \mathrm{H}$-Tyrosins und ${ }^{3} \mathrm{H}-\mathrm{N}$-Acetylserins in Tabakblättern nach Inkubation bei $23^{\circ} \mathrm{C} . \times-\times$ Tyrosin, extrahiert mit Äthanol, O-O Tyrosin, extrahiert mit Wasser, $\triangle-\triangle N$-Acetylserin, ZPM = Zerfälle pro Min. (korr.).

Konzentrationsgefälle aus der umgebenden Lösung diese Aminosäure in die Zelle einschleust. $N$-Acetylserin ist kein normaler Metabolit und daher besitzt die Zelle kein Transportsystem für diese Verbindung. Der Eintritt des $N$-Acetylserins kann daher nur durch Diffusion erfolgen. Der schnellere Anstieg der Radioaktivität des Tyrosins am Anfang könnte darauf beruhen, daß zusätzlich zum aktiven Transport

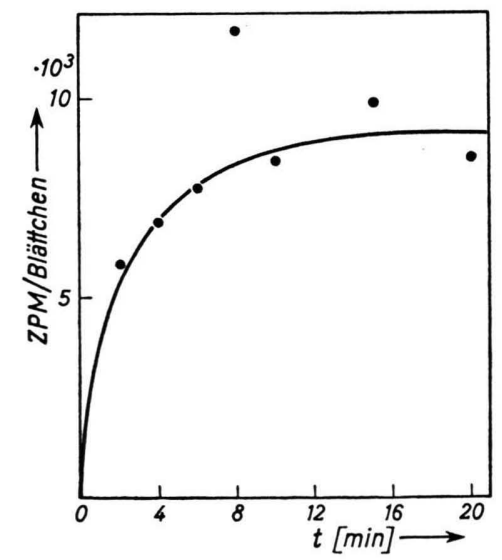

Abb. 5. Austritt des ${ }^{3} \mathrm{H}$-Tyrosins aus den Tabakblättern in das Außenmedium bei Zimmertemperatur. 
noch Diffusion stattfindet. Um dies zu prüfen, wurden Tabakblättchen, die freies radioaktives Tyrosin enthielten, in einem Medium mit einem großen Überschuß an inaktivem Tyrosin inkubiert. Aus Abb. 5 ist ersichtlich, daß tatsächlich freies radioaktives Tyrosin in das Außenmedium austritt und daß dieser Prozeß ebenfalls nach spätestens 10 Min. abgeschlossen ist. Nach diesen Vorversuchen darf man damit rechnen, daß nach 10 Min. der Ausgleich der spezifischen Radioaktivität zwischen Zellinnerem und Außenmedium durch Diffusion beendet ist und dann nur noch der aktive Transport der gleichmäßig markierten Aminosäure eine Rolle spielt.

\section{Temperaturabhängigkeit der Proteinsynthese}

Um die günstigste Einbautemperatur zu bestimmen, wurde bei verschiedenen Temperaturen der Einbau von ${ }^{3} \mathrm{H}$-Tyrosin in das Hüllprotein des Virus für jeweils 30 Min. bestimmt. Es ergab sich ein ausgeprägtes Maximum der Synthesegeschwindigkeit bei $28{ }^{\circ} \mathrm{C}$ (Abb. 6). Bei $15{ }^{\circ} \mathrm{C}$ war die Synthese-

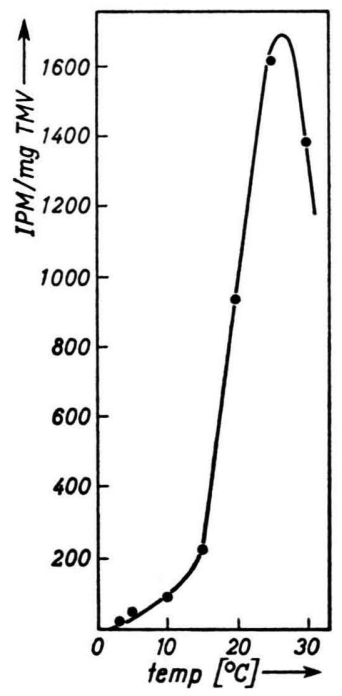

Abb. 6. Temperaturabhängigkeit des Einbaus von ${ }^{3} \mathrm{H}-\mathrm{T} y r o s i n$ in das TMV. Ipm = gezählte Impulse pro Min. (unkorr.).

geschwindigkeit auf $1 / 8$, bei $10^{\circ}$ auf $1 / 16$ verlangsamt. Diese Temperaturabhängigkeit der Virussynthese stimmt mit den Befunden von Bryan et al. ${ }^{14}$ überein.

Die Wachstumsgeschwindigkeit ganzer Pflanzen zeigt meist ein sehr breites Temperaturoptimum.

14 J. K. Bryan, B. Shearer u. B. Commoner, Virology 22, 67 [1964].
Dies könnte aber dadurch vorgetäuscht sein, daß es sehr schwierig ist, eine größere Anzahl ganzer Pflanzen in einem beleuchteten Thermostaten auf genau der gleichen Temperatur zu halten.

\section{Verteilung des ${ }^{3}$ H-Tyrosins in der Peptidkette}

Um einen Aktivitätsgradienten in der Peptidkette des TMV feststellen zu können, muß die spezifische Aktivität der Aminosäuren bei bestimmten Positionen am Anfang und Ende der Kette gemessen werden. Günstige Verhältnisse ergaben sich vor allem für das Tyrosin, das sich in den Positionen 2, 70, 72 und 139 findet (Abb. 1). Nach der tryptischen Spaltung finden sich Tyrosine in vier verschiedenen Peptiden, die gut voneinander zu trennen sind. Wegen der zu erwartenden hohen Geschwindigkeit der Peptidsynthese und den entsprechend kurzen Inkubationszeiten, muß mit möglichst hoch markierten Aminosäuren gearbeitet werden. Tyrosin ist mit großer spezifischer ${ }^{3} \mathrm{H}$-Aktivität (bis zu $38 \mathrm{C} / \mathrm{mM}$ ) zu erhalten. Nach Inkubation der Tabakblätter mit dem hoch-markierten ${ }^{3} \mathrm{H}$-Tyrosin wurden die Blattscheiben homogenisiert und mit Phosphatpuffer extrahiert. Hierbei wurde jeder Probe eine genau bekannte Menge Virus hinzugefügt, das gleichmäßig mit ${ }^{14} \mathrm{C}$-Tyrosin markiert war. Das ${ }^{3} \mathrm{H}$-markierte Virus wurde mit dem ${ }^{14} \mathrm{C}$-markierten Trägervirus $\mathrm{ab}$ zentrifugiert, das Protein durch Phenolextraktion von der Nucleinsäure getrennt, mit Trypsin abgebaut und dann das Verhältnis von ${ }^{3} \mathrm{H} /{ }^{14} \mathrm{C}$-Aktivität in den vier verschiedenen Tyrosin-haltigen Peptiden gemessen. Bei der Auftrennung der ${ }^{3} \mathrm{H}-\mathrm{Tyrosin}$-haltigen Peptide ergaben sich zunächst Schwierigkeiten, da das ${ }^{3} \mathrm{H}$, das sich in ortho-Stellung zur phenolischen $\mathrm{OH}$-Gruppe befindet, im sauren Medium gegen $\mathrm{H}$ ausgetauscht wird. Schließlich gelang es jedoch, eine Aufarbeitungsmethode zu finden, bei der alle vier tryptischen Peptide ohne Verlust an ${ }^{3} \mathrm{H}$ Aktivität isoliert werden konnten. Es wurde zunächst das tryptische Peptid mit den Positionen 1-41 bei $p_{\mathrm{H}} 4,2$ ausgefällt, dann die übrigen drei Peptide durch eine Säulenchromatographie an Sephadex G$25, p_{\mathrm{H}} 8-8,5$, abgetrennt.

Um die Sicherheit und Genauigkeit der Methode festzustellen, wurden eine Reihe von Kontrollversuchen durchgeführt, die im Versuchsteil näher beschrieben sind. Ein Aktivitätsunterschied von 20\% in den Tyrosin-Positionen sollte hiernach mit Sicherheit meßbar sein. Nach diesen Vorversuchen wurden Scheibchen aus infizierten Tabakblättern mit ${ }^{3} \mathrm{H}$ - 
Tyrosin bebrütet. Um den Einbau möglichst langsam ablaufen zu lassen, wurde eine Versuchstemperatur von $10^{\circ} \mathrm{C}$ gewählt. Das Ergebnis ist in Abb. 7

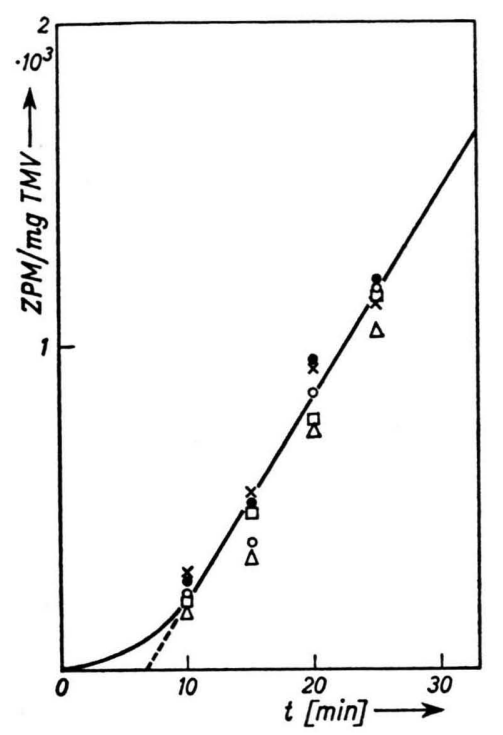

Abb. 7. Spezifische Aktivität des Tyrosins in verschiedenen Positionen der Peptidkette in Zerfällen/min/mg TMV. $\times$ Position 2, $\triangle$ Position 70, $\square$ Position 72, $\circ$ Position 139, - ${ }^{1 / 4}$ der Gesamtaktivität/mg TMV.

wiedergegeben. Die kürzeste Versuchszeit betrug 10 Min., da bei noch kürzeren Versuchszeiten die Radioaktivität zu gering ist, um noch sichere Meßwerte zu liefern. Nach diesem Zeitintervall war bereits die Aktivität in allen vier Positionen gleich und stimmte mit dem Durchschnittswert, der $1 / 4$ der Gesamtaktivität des Proteins entspricht, überein. Ein Aktivitätsgradient ließ sich bei keinem Versuch feststellen.

\section{Verteilung des ${ }^{3} \mathrm{H}$-Prolins in der Peptidkette}

Die schnelle, gleichmäßige Markierung der gesamten Peptidkette auch bei kurzen Versuchszeiten trat in gleicher Weise auf, wenn statt ${ }^{3} \mathrm{H}$-Tyrosin ${ }^{3} \mathrm{H}$-Prolin verwendet wurde. Diese Aminosäure ist ebenfalls mit hoher spezifischer ${ }^{3} \mathrm{H}$-Aktivität zu erhalten, das ${ }^{3} \mathrm{H}$ ist jedoch sehr fest gebunden, so daß es auch bei saurer Lösung nicht austauscht.

Durch Säurefällung wurde ein Peptid abgetrennt, das die Positionen 7 und 21 enthielt. Durch Elektrophorese konnten dann drei weitere Peptide getrennt werden, von denen das kathodisch wandernde die Prolin-Positionen 54 und 56 und die beiden anodisch wandernden die Positionen 63 bzw. 102 enthielten.
Zur Messung der Proteinmenge wurde wieder TMVProtein zugegeben, das in allen Prolin-Positionen gleichmäßig mit ${ }^{14} \mathrm{C}$ markiert war. Die Inkubationsversuche mit ${ }^{3} \mathrm{H}$-markiertem Prolin wurden bei $15^{\circ}$ durchgeführt. Die Versuchszeit konnte bis auf 5 Min. herabgesetzt werden. Dennoch waren zu diesem Zeitpunkt bereits alle Positionen in der Peptidkette gleichmäßig mit ${ }^{3} \mathrm{H}$ markiert (Abb. $8 \mathrm{a}$ ).
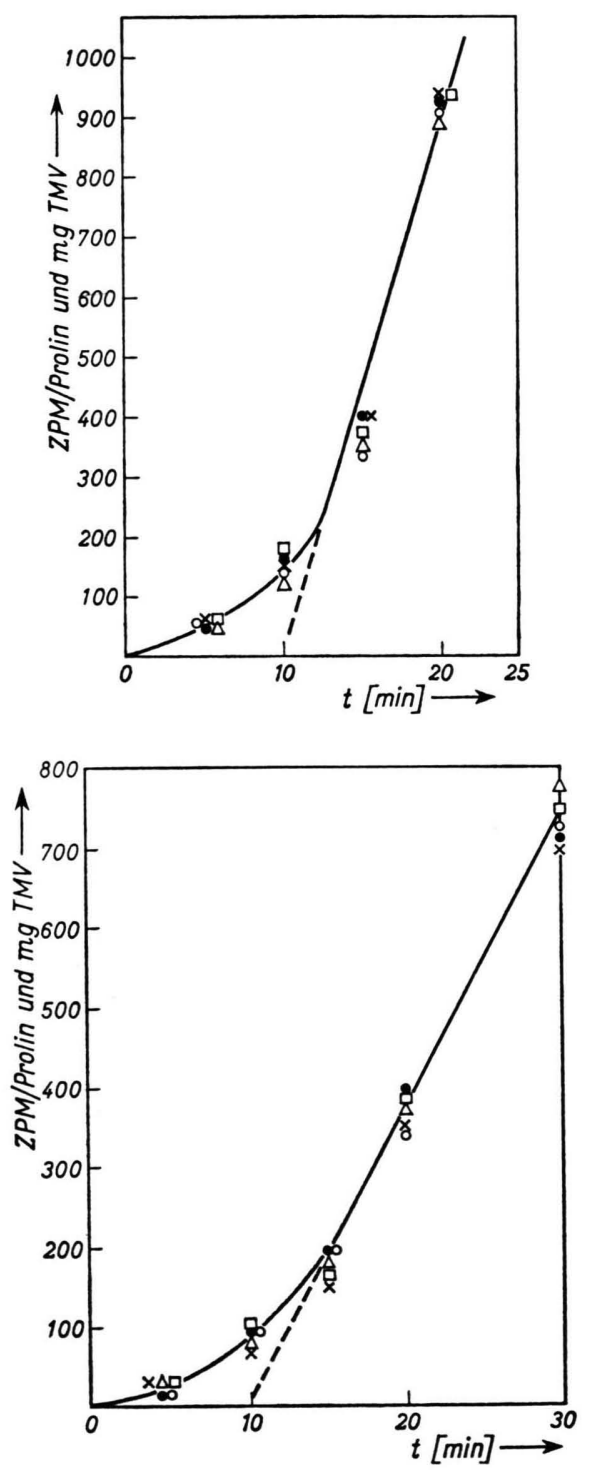

Abb. 8. a) Spezifische Aktivität des Prolins in verschiedenen Positionen in vollständigen Virusteilchen, die bei $p_{\mathrm{H}} 7 \mathrm{abzen}$ trifugiert sind. b) Spezifische Aktivität des Prolins in verschiedenen Positionen des löslichen Virusproteins, das bei $p_{\mathrm{H}} 5,5$ aggregiert wurde. $\times 1 / 2$ Position $(7+21), \triangle^{1 / 2}$ Position (54 $+56), \square$ Position 63, ○ Position 102, $1 / 8$ der Gesamtaktivität/mg TMV. 
Es wurde weiterhin geprüft, ob in dem löslichen, nicht zu Virusteilchen aggregierten Protein ein Aktivitätsgradient festzustellen war. $\mathrm{Zu}$ diesem Zweck wurde das Blatt homogenisiert, nach dem Abzentrifugiern der Virusteilchen nochmals mit inaktivem Virus versetzt und das lösliche Protein durch $p_{\mathrm{H}^{-}}$ Verschiebung auf $p_{\mathrm{H}} 5,5 \mathrm{zu}$ Stäbchen aggregiert, die dann nach Zusatz von Trägervirus abzentrifugiert wurden. Dieses Material wurde durch differentielle Zentrifugation und isoelektrische Fällung gereinigt und auf seinen ${ }^{3} \mathrm{H}$-Gehalt in den verschiedenen Prolin-Positionen untersucht. Auch in dem löslichen Virusprotein hatte sich bereits nach 5 Min. eine Gleichverteilung in allen Prolin-Positionen eingestellt (Abb. 8 b).

\section{Diskussion}

Die um 50\% erhöhte Synthesegeschwindigkeit im Virus-bildenden Blatt findet eine Parallele in den Versuchen von Hayashi ${ }^{15}$, der in Extrakten aus infizierten Pflanzen eine um 50\% gesteigerte Aktivierung von Aminosäuren gegenüber den Extrakten aus gesunden Pflanzen fand. Die zusätzliche Proteinsynthese beruht zu $60 \%$ auf der Bildung von fertigen Virusteilchen und löslichem Virusprotein. 40\% der Erhöhung könnte durch Induktion spezifischer Enzyme verursacht sein, die nicht in das Virus eingebaut werden, so daß die gesamte Erhöhung der Proteinsynthese auf die Bildung Virus-induzierter Proteine zurückgeführt werden könnte. Eine Verminderung der Bildungsgeschwindigkeit der Wirtsproteine wurde nicht beobachtet. In dieser Hinsicht unterscheidet sich also das TMV von kleinen RNShaltigen Viren tierischer Zellen, bei denen eine Hemmung der normalen Proteinsynthese beobachtet wurde $^{16}$.

Die ungestörte Proteinsynthese könnte auch der Grund dafür sein, daß im vorliegenden Fall die Tabakzelle trotz der hohen Virusproduktion nicht zerstört wird.

Der Ausgleich der Radioaktivität zwischen den freien Aminosäuren im Zellinnern und im Außenmedium ist erst nach 10 Min. erreicht. Er erfolgt anfangs schnell, dann langsamer (s. Abb. 4). Wegen der anfangs geringen spezifischen Aktivität der Aminosäuren im Zellinnern steigt die Radioaktivität

15 Y. HAYASHI, Virology 18, 140 [1962].

16 P. Hausen u. D. W. Verwoerd, Virology 21, 617 [1963], dort weitere Literatur. im Protein zunächst langsam an, bis dann nach etwa 10 Min. die eingebaute Radioaktivität linear mit der Zeit und ziemlich schnell zunimmt. Dies ist sowohl beim Tyrosin (Abb. 7) als auch beim Prolin (Abbn. $8 \mathrm{a}$ und b) zu beobachten.

Da nach 5 Min. bei $15{ }^{\circ} \mathrm{C}$ oder nach 10 Min. bei $10^{\circ} \mathrm{C}$ alle Positionen der Peptidkette bereits gleichmäßig markiert sind, muß die Wachstumsgeschwindigkeit der Peptidkette sehr hoch sein. Nach den oben erwähnten theoretischen Überlegungen bedeutet dies, da $\beta$ die Synthesezeit $t_{\mathrm{s}}$ wesentlich kleiner als die Versuchszeit $T$ sein muß. Aus der Abschätzung der Fehlergrenzen ergibt sich, daß ein Aktivitätsunterschied von $20 \%$ zwischen Kettenanfang und Kettenende mit Sicherheit meßbar gewesen wäre. Wäre $t_{\mathrm{s}}=T$, so würde der Aktivitätsunterschied $100 \%$ des gemessenen Werts betragen $(\Delta R=R)$. Eine Differenz von $20 \%$ wäre zu erwarten bei $t_{\mathrm{s}}=T / 5$. Demnach müßte also die maximale Synthesezeit bei $15{ }^{\circ} \mathrm{C}$ unterhalb einer Min. liegen. Dies würde einer minimalen Einbaugeschwindigkeit von 4. Aminosäuren/sec entsprechen. Dieser Schluß wird nicht dadurch beeinträchtigt, daß während der Synthesezeit die spezifische Aktivität im AminosäureSammelbecken ansteigt. Wie weiter unten gezeigt wird, kann dies nur zu einer Erhöhung des scheinbaren Aktivitätsgradienten führen. Da die Synthesezeit bei $15^{\circ}$ etwa 8-mal größer ist als bei der optimalen Temperatur von $28{ }^{\circ} \mathrm{C}$, könnte die Synthesezeit für die TMV-Kette unter optimalen Bedingungen bei 8 Sek. liegen, was einer Wachstumsgeschwindigkeit von 20 Aminosäuren/sec entsprechen würde. Sie wäre demnach etwa von der gleichen Größenordnung wie die bei Escherichia coli, die sich nach den im Versuchsteil angegebenen Daten zu etwa 40 Aminosäuren/sec berechnet. Hierbei ist allerdings vorausgesetzt, daß die erhöhte Einbaurate bei $28^{\circ} \mathrm{C}$ ausschließlich durch das schnellere Kettenwachstum bedingt ist und nicht durch die Zunahme der Zahl der aktiven Ribosomen. Da aber in tierischen Zellen eine starke Temperatur-Abhängigkeit des Kettenwachstums gefunden wurde, dürfte dies auch für die Pflanzenzelle zutreffen. Es ist bemerkenswert, daß auch in dem nicht-aggregierten Hüllprotein nach 5 Min. bei $15{ }^{\circ} \mathrm{C}$ eine gleichförmige Markierung des Prolins über alle Positionen festzustellen ist. Die Gleichverteilung im fertigen Virusteilchen beruht also nicht auf einer Verwischung der Aktivitätsunterschiede bei der Aggregation der Untereinheiten zu Stäbchen. Eine solche Verwischung könnte auf- 
treten, wenn die fertigen Peptidketten in einem großen Sammelbecken durcheinander gemischt werden und aus diesem erst langsam das fertige Virusteilchen entsteht.

Die Biosynthese des TMV-Hüllproteins bei $15^{\circ} \mathrm{C}$ verläuft auf jeden Fall wesentlich schneller als die des Hämoglobins in Reticulocyten bei gleicher Temperatur. Diese Tatsache wird durch Abb. 9 verdeut-

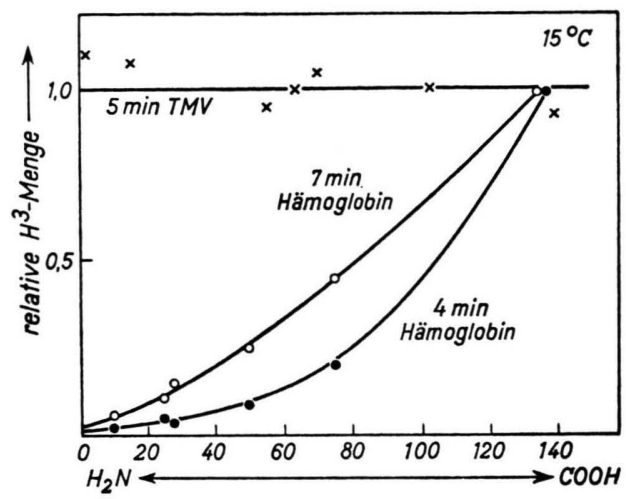

Abb. 9. Verteilung der spezifischen Radioaktivität entlang der Peptidketten des TMV und des Hämoglobins nach kurzzeitiger Inkubation bei $15{ }^{\circ} \mathrm{C}$. $\bullet$ Hämoglobin nach 4 Min., ○ Hämoglobin nach 7 Min., $\times$ TMV nach 5 Minuten. Die Abszisse gibt die Positionen in der Peptidkette wieder, die Ordinate die relative Aktivität. Beim TMV wurde der Mittelwert der Aktivität $=1$ gesetzt.

licht. Beim Hämoglobin ist noch nach einer Versuchszeit von 7 Min. ein deutlicher Aktivitätsgradient nachweisbar, während beim TMV-Protein bereits nach 5 Min. die Radioaktivität gleichförmig verteilt ist. Auch bei der Lysozymsynthese im Ovidukt wurde bei $37{ }^{\circ} \mathrm{C}$ nach 5 Min. noch ein deutlicher Aktivitätsgradient festgestellt ${ }^{3}$. Ähnliche Verhältnisse ergaben sich bei der Biosynthese der Ribonuclease im Pankreas ${ }^{6}$ und bei der Biosynthese des Insulins ${ }^{7}$. Der Grund für die relativ langsame Proteinsynthese in Warmblüterzellen ist nicht bekannt. Nach KNopF und LAMFrom $^{12}$ ist für die Hämoglobinsynthese wahrscheinlich die einleitende Reaktion, z. B. die Anlagerung der Ribosomen an die messenger-RNS Geschwindigkeits-bestimmend. Man könnte sich vorstellen, daß bei Pflanzen und bei Bakterien die viel häufiger und schneller auf veränderte Umweltsverhältnisse reagieren müssen als die homöostatisch regulierten Warmblüter, die Anfangsreaktion der Proteinsynthese anders verläuft als in der tierischen Zelle. Hier ergeben sich noch interessante Möglichkeiten für vergleichende Untersuchungen.
Versucht man die Geschwindigkeit der Peptidsynthese im Tabakblatt aus der Einbaugeschwindigkeit des Tyrosins in das gesamte Protein infizierter Tabakblätter und aus der Zahl der vorhandenen Ribosomen zu berechnen, so ergibt sich eine Synthesegeschwindigkeit von nur 0,1 Aminosäuren je Sekunde. Da kaum anzunehmen ist, daß die Synthese des Normalproteins sehr viel langsamer verläuft als die Synthese des Virusproteins, darf man wohl schließen, daß nur ein kleiner Teil der in den Tabakblättern vorhandenen Ribosomen an der Proteinsynthese beteiligt ist. Hier besteht also ein deutlicher Unterschied gegenüber $E$. coli, bei dem unter günstigen Wachstumsbedingungen wahrscheinlich alle Ribosomen an der Proteinsynthese teilnehmen.

In Abb. 9 fällt auf, daß beim Hämoglobin der Aktivitätsgradient nicht linear verläuft, sondern zum Ende der Peptidkette hin ansteigt. Diesen Verlauf sollte man erwarten, wenn während der Versuchszeit die spezifische Aktivität der freien Aminosäuren zunimmt. Am C-Ende werden bis zuletzt Aminosäuren aus dem Sammelbecken eingebaut. Diese müssen daher eine höhere spezifische Aktivität besitzen als die in den niedrigeren Positionen eingebauten und so entsteht eine gekrümmte Aktivitätskurve. Eine solche gekrümmte Kurve wurde auch von InGRAM et al. ${ }^{10}$ bei der Biosynthese des Hämoglobins im menschlichen Rückenmark erhalten. Sie schließen daraus, daß die Synthesegeschwindigkeit zum Kettenende abnimmt und daß in der Nähe der Position 50 ein Kontrollpunkt vorliege, der die Wachstumsrate vermindert (s. hierzu auch l. c. ${ }^{17}$ ). Dieser Schluß erscheint recht fragwürdig, solange der Anstieg der spezifischen Aktivität der freien Aminosäuren in diesem System nicht berücksichtigt ist. Von anderer Seite ${ }^{18}$ wurde gezeigt, daß der Ausgleich der Radioaktivität zwischen den freien Aminosäuren in Kaninchen-Reticulocyten und dem Außenmedium bei $37^{\circ} \mathrm{C}$ einen Zeitraum von $1-2$ Min. erfordert. Die Nicht-Linearität des Aktivitätsgradienten könnte also durch diesen langsamen Austausch bedingt sein. Hierfür sprechen auch die Versuche von Canfield und Anfinsen ${ }^{3}$. Sie fanden beim Lysozym einen linearen Gradienten, wenn das Gewebe bei tiefer Temperatur mit der markierten Aminosäure vorinkubiert wurde, dagegen einen gekrümm-

17 S. W. Englander u. L. A. Page, Biochem. biophysic. Res. Commun. 19, 565 [1965].

18 I. R. W 
ten Gradienten, wenn kein vorheriger Austausch stattgefunden hatte.

Die vorliegende Untersuchung läßt die experimentellen Schwierigkeiten erkennen, die bei der Bestimmung der Proteinsynthese in intakten Pflanzenzellen bestehen. Da die Proteinsynthese sehr schnell verläuft, müßten zur Feststellung des Aktivitätsgradienten sehr kurze Versuchszeiten gewählt werden. Auch bei Verwendung höchst markierter Aminosäuren würden dann nur geringe Aktivitäten in der Peptidkette erscheinen, die unterhalb der Meß- genauigkeit lägen. Ungünstig wirkt sich weiterhin aus, daß sich von den angebotenen Aminosäuren höchstens $30 \%$ im Virusprotein wiederfinden und $\mathrm{da} ß$ der Austausch der freien Aminosäuren nur langsam erfolgt. Bei der Untersuchung zellfreier Systeme werden diese Fehlerquellen wesentlich geringer, doch blieb dann fraglich, inwieweit die in vitro gewonnenen Ergebnisse auf die lebende Zelle übertragbar sind.

Die Arbeit wurde vom US Public Health Service (Grant Nr. 5 R01 CA 04601-07) unterstützt.

\title{
Elektronenanlagerungs-Massenspektrographie und Thion-Thiol-Umlagerung
}

\author{
R. MAYer und P. Rosmus \\ Institut für Organische Chemie der Technischen Universität Dresden \\ M. von Ardenne, K. Steinfelder und R. Tümmler \\ Forschungsinstitut Manfred von Ardenne, Dresden-Weißer-Hirsch \\ (Z. Naturforschg. 22 b, 1291-1295 [1967] ; eingegangen am 13. April 1967)
}

\begin{abstract}
Die Elektronenanlagerungs-Massenspektrographie erwies sich als ein geeignetes Mittel zur Untersuchung der Thion-Thiol-Umlagerung in Thioncarbonaten und Thioharnstoffen. Elementarer Schwefel $\left(S_{8}\right)$ bildet unter den angeführten experimentellen Bedingungen negative Ionen von $S_{2} \ominus$ bis $\mathrm{S}_{6}{ }^{\ominus}$, während $\mathrm{S}_{7} \ominus$. und $\mathrm{S}_{8} \ominus$.Ionen nur in sehr geringer relativer Häufigkeit nachweisbar sind.
\end{abstract}

In der vorliegenden Arbeit wird die Elektronenanlagerungs-Massenspektrographie (EA-Massenspektrographie) ${ }^{1-3}$ zur Untersuchung der Thion-ThiolUmlagerung

$$
-x-c-i d x
$$

von Thioncarbonaten (II) und Thioharnstoffen (III) bzw. (IV) angewendet. Zum Vergleich werden die EA-Massenspektren des Diphenyltrithiocarbonats (I) und des elementaren Schwefels aufgenommen.

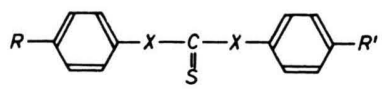

$$
\begin{array}{ll} 
& \mathrm{I}: \quad \mathrm{X}=\mathrm{S} \\
& \mathrm{II}: \quad \mathrm{X}=\mathrm{O} \\
& \mathrm{III}: \quad \mathrm{X}=\mathrm{NH} \\
\mathrm{a}: & \mathrm{R}=\mathrm{R}^{\prime}=\mathrm{H} \\
\mathrm{b}: & \mathrm{R}=\mathrm{R}^{\prime}=\mathrm{CH}_{3} \\
\text { c: } & \mathrm{R}=\mathrm{R}^{\prime}=\mathrm{NO}_{2} \\
\mathrm{~d}: & \mathrm{R}=\mathrm{NO}_{2} ; \quad \mathrm{R}^{\prime}=\mathrm{H} \\
\mathrm{e}: & \mathrm{R}=\mathrm{CH}_{3} \mathrm{O} ; \quad \mathrm{R}^{\prime}=\mathrm{H} \\
\mathrm{f}: & \mathrm{R}=\mathrm{Cl} ; \mathrm{R}^{\prime}=\mathrm{H}
\end{array}
$$

1 M. v. Ardenne, Tab. zur Angew. Phys. Bd. I, Dtsch. Verlag d. Wiss., Berlin 1962.

2 R. Tümmler, Z. physik. Chem. 229, 58 [1965].

3 M. v. Ardenne, K. Steinfelder u. R. Tümmler, Z. Chem. 5, 287 [1965].

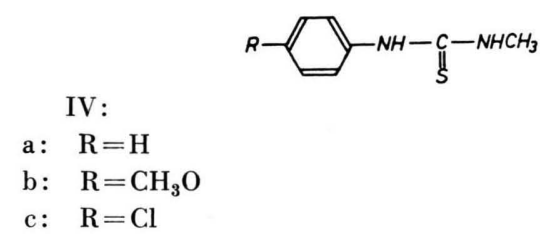

Die hochaufgelösten Spektren der positiven Ionen einiger Vertreter der Typen I und II sind kürzlich von DJerassi et al. ${ }^{4}$ diskutiert worden. Die von uns beobachteten Fragmentierungs-Mechanismen in den EA-Massenspektren der negativen Ionen ähneln denen der durch Elektronenstoß (ES) erzeugten positiven Ionen. EA- und ES-Massenspektren ergänzen sich insofern, als jeweils die schwachen Peaks der einen Ionenart bei der anderen sehr intensiv auftreten. Daraus ergibt sich die Möglichkeit, das charakteristische Verhalten beider Verfahren auch zur Strukturuntersuchung unbekannter Substanzen auszunützen ${ }^{5}$.

4 J. B. Thomson, P. Brown u. C. Djerassi, J. Amer. chem. Soc. 88, 4049 [1966].

5 S. Huneck, C. Djerassi, M. v. Ardenne, K. Steinfelder u. R. Tümmler, Tetrahedron Letters [1967], im Druck. 